\title{
How Useful Photography is in Sociological Researches on Ethnic Identity Studies?
}

\section{Krishna P Pandey}

\begin{abstract}
The origins of photography and sociology date back almost at the same time, but the relationship between them was not as intimate as it was to be. Sociologists refrained from using photography as a method in their researches until the importance of qualitative research was realized. Debate is still going on whether photographs expose total social reality or just provide the possibilities of subjective interpretations in the form of partial truths. Anthropologists, to some extent, are ahead in using photographs in their ethnographic works from early years. The essay deals photography only as a means of sociologists' engagement with issues of identity formation with reference to ethnicity. The narrative potentiality of photography, which is crucial to uncover the meanings embedded in peoples' struggles for identity, becomes its strength to claim as a research tool in qualitative research in sociology. Furthermore, enriched with meanings photographs bring subjectivists and constructivists closer to the discipline of photography. The importance of photography in constructing meanings through grounded theory method research on ethnic identity concerns of various cultural groups, largely in south Asia, cannot be underscored since the photographic practice has already made its claim for the place in qualitative sociology and anthropology.
\end{abstract}

Keywords: Photography, ethnicity, ethnic identity, grounded theory method, Nepal, South Asia.

\section{Photography's Entry into Qualitative Sociology}

The word photography refers-derived from the Greek phos meaning light and 'graphe' meaning drawing or writing- to the meaning drawing with light. Photography as a form of imagery representation of the world came into existence since $1840 \mathrm{~s}$. 
Sociology, largely known as a science of society, also made its formal independent appearance before us when Auguste Comte first referred to the scientific study of society as sociology in 1838. Becker (1974) asserts that sociology and photography have come into existence almost at the same time, if we acknowledge Comte's use of the word 'sociology' in 1838 as a birth of discipline of sociology, and birth of photography as 'when Daguerre made public his method for fixing an image on a metal plate' in 1839 (p. 3).

But, this single reference is less than sufficient to argue that both of these disciplines share a lot since their origin. Despite the common goal of exploring the varieties of societies, sociology primarily adopted textual form for imparting its analysis to the people and expanded its ends to moral, metaphysical as well as scientific; photography remained either as a form of artistic reflection or mirror image of realities emanated from nature and society. This is one of the points of departure from where sociology and photography caught different but parallel courses.

In initial days, preoccupied with empirical and quantitative methods of sociological research, mainstream sociologists refrained from using photography because of possible subjectivity impregnated in it. Their misconception against photography at that time was largely based on the assumption that photography lacks the ability to provide statistically verifiable facts and, even if used, provides redundant information that already extracted through other means of data collection (Campion, 2007). The reason of avoidance of photography in early sociological researches lies in the stereotyped perception of sociologists. That is, sociology in the days of Comte and thereafter was defined in accordance with the principles of natural sciences. Positivism was the spirit of sociology and human behaviour was a quantifiable entity (Campion, 2007), which was thought to be incongruent with the nature of photography.

The case for anthropology, a sister discipline of sociology from the very beginning, is quite different. Pinney (2011) traces the parallel evolution of both photography and anthropology in the middle of nineteenth century. The difference stems from the anthropologists' belief that photography would extract objective reality of social 
life. Thus early sociologists and anthropologists scared off from photography on their own ground. Despite few instances of doubt, it enormously had occupied space in ethnographic studies of early anthropologists such as E. E. Evans-Pritchard in The Nuerin 1940, and Gregory Bateson and Margaret Mead in their Balinese Character in 1942. Prior to them, Bronislaw Malinowski had made intensive use of photographs in Argonauts of the Western Pacific in 1922 and The Sexual Life of Savages in Northwestern Melanesia in 1929 (Pinney, 2011). We can trace few anthropological uses of photography even before the period of Malinowski, the brand name of participant-observation in anthropology. But, the aim of this essay is not to deal with the history of ethnographic photography per se, but just to introduce their juxtaposition.

Sociology and anthropology emerged on the backdrop of colonial domination. Anthropology was more brought to closer to the nonwestern tribal societies, sometimes tagged as 'savages' looking at the whole things from colonial lenses. The sponsorship provided for earlier ethnographies by colonial administration largely shaped the context and perspective of looking at non-western world through anthropological works. This colonial flavour has been substantially tasted even in classical anthropological works which finally put their legitimacy into question. The use of photographs in those works also could not be kept away from scope of criticism. By and large, sociology could manage to escape from such criticism because it mostly relied on large scale surveys of western social problems. Still there are too many things commonly shared by both disciplines. Whatever the intention and perspective may be, fact is the penetration of photography into both disciplines from their early years (Howard, 1974; Pinney, 2011).

In recent years, the introduction of visual sociology and visual anthropology as two sub-disciplines within sociology and anthropology has legitimised the intertwining of photography and sociology/anthropology to some extent. Various western and even non-western universities have launched academic programmes in visual sociology. The association of visual sociologists seems committed to bring sociology and photography together in the study of society, culture and social relationships. At least, camera has 
been a part of sociologists' life nowadays; and images have been increasingly used primarily in qualitative sociological researches in one or other form. One of the reasons that photography is winning the trust of sociologists is its potentiality of narrating peoples' experiences, feelings and emotions emanated from complex interplay of their various social identities.

\section{Photographs as Means of Narrating Identity}

Let's begin from what narration is. Humans are Homo Narransstorytelling animals; various scholars believe. Human life is rich with stories. They make stories in everyday interactions and live with these as well. Making and, then, living with stories do not let the chapter of life to end. They recollect these stories and share with the fellows. Thus, emerges the notion of narration. Narration is a notion related with the way of sharing experiences and feelings, and found in almost all disciplines of humanities and social sciences those deal with human social behaviours including sociology. Could photographs, then, be a means of brining the stories embedded with people's experiences out? Campbell (2010) notes that 'narratives are not found in objects either' rather they are constructed by analysts, interpreters and narrators. Since narratives come through construction, they are attached to the idea of context in photography (ibid). Although narratives are constructed in various forms, the classical form is linear narrative having a story with beginning, middle and end. In this sense, one can ask if photography grasp such linearity and temporality of the stories with reference to people's identities.

The centrality of narrating identity through photography lies in the degree of representation and truth that it conveys. Identity, in this context, is a sort of self-awareness of one's location and attachment in wider network of social relationships. It is still not possible to make concrete claim whether utter truth exists. Even if we claim, postmodernists would put us in trouble. So, representation of truth necessarily involves only representing subjective truth claims, which is partial in itself. Not only photography but text also cannot claim the totality of truth. Truth is relative and context bound. When photographs are arranged in a sequence they tell a story (Wolbert, 
2000), which could be a medium of churning people's experiences out from their daily lives. For instance, simply, sequential viewing of an individual's photographs not only provides ethnographic details to an anthropologist but also reveals the complex pattern of changes in his/her social positioning.

Pimenta and Poovaiah (2010) have used a different phrase, visual narrative, to refer to the way stories are delivered through visual aids such as photography. Similarly, Murray (1995) has rephrased 'narrative illustration' to 'the pictorial representation of or reference to one or more "events" that occur in a sequence of time and that bring about a change in the condition of at least one character' (p.17). These instances also inspire us to think over the utility and strength of images in constructing and narrating stories. Another way of understanding photography from narrative perspective is the assumption that photographs themselves are repositories of stories.

Contrary to few scholars' belief, photographs (other forms of imagery representations also) are not dead, static and passive representations of reality. Rather, as in Roland Barthes' words, 'the [p]hotography mechanically repeats what could never be repeated existentially' (Barthes, 1984, p. 4) by bringing dead events (literally, past events) to the present and linking with larger social milieu. Rarely people disagree that photographs inscribe our memories, experiences, sufferings and pains in them. They have become effective means of winning emotions by letting people engage in nostalgia. Thus, photography has gained its identity as intermediary between people, events and their reminiscences.

Human beings need a medium to narrate the stories developed from their struggles for locating positions in larger social network. Since people need to engage with multitude of social interactions, they construct various social identities simultaneously such as based on gender, class, ethnicity, religion, and education and so on. Entangled in a complex network of identities, they develop complicated forms of stories. Besides oral narration, photography is equally powerful means of telling people's stories in the form of images. Then, the further discussion on the practicality of using photos in studying culturally rooted identities such as ethnicity may help to validate the narrative potentiality of photography in sociology. 


\section{Practical Aspects of Using Photos in Research on Ethnicity}

Researchers interested in ethnic identity largely follow two broad traditions of research: quantitative and qualitative. Quantitative researchers either emphasize survey type statistical assessment of various aspects of ethnic identities such as constructing indicators and scales. But qualitative researchers try to contextualize the identity issues with larger socio-cultural and political situations from both researchers' and participants' perspectives. Furthermore, they are also found engaged in constructing the meanings from people's narration of their past and present. In a sense, engagement with ethnic identity from qualitative perspective is a reflexive process in itself. Such constructivist orientation of meaning making from the interactive process between the researcher and research participants is dominant paradigm in researches on ethnic identity. Since subjectivity is the central feature of ethnic identity, sociological researches cannot avoid the significance of pictorial representation of social life. Images have an integral association with human civilization since its very beginning. People from early stages of civilization have made hard efforts to get them represent their social life through cave paintings, stone and wood carvings and so on.

Photography is one of the, but recent, several forms of pictorial representation of social life. The usage of camera in social research is still contested on the ground of objectivity versus artistic expressions that photographs are supposed to reflect. The controversy resulted in the marginalization of photographic research within larger disciplines. But, by the 1980s social sciences including sociology and anthropology started to move away from rigid scientific inclination towards a fuller understanding of reflexivity and subjectivity (Marion \& Crowder, 2013). This priority shift ultimately affected the practice of visual research, 'with ethnographic film makers and photographers recognizing their inherently subjective positioning at all stages in the production, use, and analysis of images' [photographs] (ibid: 45).

Photography has been established as a powerful means of self-representation for ethnic groups in the various parts of the world. Kinsman's (1995) observation is that '[m]uch of the black 
photography in Britain in the 1980s has been concerned with [...] issues of self-representation' (p. 307). Such efforts are, sometimes, understood as the move in the politics of representation (ibid). The root of ethnic identity above all rests on politics of representation and recognition on broader cultural context. Photography can sustain or challenge the stereotype images of ethnic categories. The way dominant media use photographs to construct the images of cultural groups of a nation brings the identity issues into the public discourse by making it politically and culturally susceptible. In such circumstances, photographs themselves could be the potential subject of research, but not only the means for research.

Increasing usage of photographs in media, books, journals and internet nowadays leads us not to think photographs only as illustrations. Like field notes a social researcher writes during his/ her field visit, visual field notes also constitute a rich source of data. Photographs are data in their own right (Marion \& Crowder, 2013). They do not intend to replace textual data by photographs but suggest using in conjunction to delve into deeper understanding of socio-cultural dynamics. Another equally important point is that all research questions cannot be answered merely by photographic data, rather it depends on the nature of answer a research question expects.

Same is applicable in research on ethnic issues with the aid of images. It doesnot mean that photographs only provide data on physical setting, but as Pink (2006) cited in Marion \& Crowder(2013, p. 29) stated, visual methods and data such as photographs 'can be especially pertinent in investigating embodied experiences' including the feelings and experiences generated from an ethnic position of an individual in larger social network. Though it is implicit, visual data have longstanding tradition in the form of sketches and diagrams even before modern photography and videography (Marion \& Crowder, 2013). Since 'image speaks directly to the senses and emphasizes the human body and objectifications of culture and social aesthetics and social interaction, instead of ideas, meanings, and concepts' (Postma \& Crawford 2006, p. 2) cited in Marion and Crowder (2013, p. 29) the use of photographs as a form of imagery representation of embodied 
experiences of people's ethnic consciousness can sufficiently be a part of practicality of sociological researches.

Camera is generally taken as 'mirror with a memory' rather than a 'mirror of reality' (English 1988, p. 8). So, qualitative researchers prefer to use camera to capture images of social processes, social interaction and relationships. Most of the social relationships are discussed in the verbal communications assuming that the social positions of the participants in interaction is self understood (Collier \& Collier, 1986) but there are several aspects of social relationships people are unaware of (ibid). This is not the case always and visual observation is required to experience this level of social relationship. For instance, Collier \& Collier (1986) note that photographs of 'clothing provides evidence for the comparison of ethnic groups and social organizations ....' (p. 82). When we study ethnicity through photography, it should capture the temporal flow that tracks changes and continuity of the behavior of ethnic people. This temporal flow helps understand the pattern of changes in social interaction and the role of the actors with ethnic out-groups and within ethnic in group itself.

The importance of camera and photographs in research on ethnicity is justified when researchers gain success in recording ethnic relationships to seek formal and informal associations of ethnic out groups intertwined with national social network reflecting their various identities. Interviewing with photographs (i.e., photo elicitation) for the most part differs from conventional verbal interview in participatory field setting and with ethnically sensitive communities. Verbal interviews may create distance between interviewer and participants; between participant and the event that the photograph is concerned, whereas use of the photograph brings these them closer (Collier \& Collier, 1986). Photo elicitation interviews are relatively non-threatening because the interview participants 'express themselves through an interpersonal and socially acceptable communication medium' (Schulze 2007, p. 540).

The viewing of photograph is an interactive process; so meaning from a photograph is constructed through the interaction of image, spectator and the photographer; not already embedded there in 
the photo. Schwartz is of the view that viewing and interpreting photography is a social activity that specifically requires context, cultural conventions and group norms (Schwartz, 1989). This becomes more instrumental in while tapping sensitive information from difficult situation where ethnic contention is shaping the nature of social interaction. By and large, photographs help researchers create reflexive environment based on trust and mutuality by breaking the emotional barriers between them and the ethnic participants leading to the production of subjective interpretations of the events and processes in which the participants are engaged with.

The question of practicality of using photos rests on the nature of meanings that they impart. Qualitative researchers have already acknowledged that interpreting photographs is an interactive process. This leads to the construction of meanings through the interaction of image, viewer and the photographer, which in itself a central element of subjectivist and constructivist understanding in sociology. Constructing meanings from imagery representation of social life on the backdrop of time and context is not illegitimate way of sociological studies because the notion of complete truth has lost its legitimacy at least in qualitative researches on identity concerns in which individual subjectivity is deeply entrenched.

\section{Facts, Photographs and Interpretation in Qualitative Research on Ethnicity}

The ongoing debate between qualitative and quantitative sociologists since the early years of disciplinary formation substantially rests on the nature of social fact or social reality. John R. Searle (1995), while discussing on the building blocks of social reality in his book entitled The Construction of Social Reality contrasts two types of facts; institutional and non-institutional or bare facts. In Searle (1995)'s own words:

Institutional facts are so called because they require human institutions for their existence. In order that this piece of paper should be a five dollar bill, for example, there has to be the human institution of money. Brute facts require no human institutions for their existence. Of course, in order to state a brute fact we 
require the institution of language, but the fact stated needs to

be distinguished from the statement of it (emphasis in original) (p. 2).

Despite the questions such as how such facts are possible and what the structure of such facts are still puzzling the scholars, both of these facts are connected with human consciousness and sense of meaning making largely governed by their feelings and experiences. Fact or reality in this sense is not absolutely independent from human emotion and experience that they attach with the respective social identities. Searle (1995) argues that the weightless and invisible nature of social reality makes it complex in its structure. Facts, feelings, experiences and identity are the product of human consciousness; and consciousness itself is largely intentional. This is how social reality comes to be of subjective nature.

Though they may have physical existence or may not (in digital photography), photographs can be considered as material entity unless they are brought to the interpreter (either they may be viewers or a photographer). Photographs bridge the social reality and people's identity through interpretation. Qualitative researchers do not believe in objective interpretation, rather hold the view that interpretation of social realities including photographs is by nature subjective. As discussed elsewhere, the time and context shape the meaning a photograph is assigned to. The other important aspect of photographic interpretation is the identity of the interpreter or viewers. The way a viewer understands a photo in different time and context constructs different meanings and emotions are generated accordingly.

Interpreting photos means constructing meanings from them in which the activities of looking, seeing, and knowing are inextricably intertwined. As a result, photographs show many things at once by making the interpretation powerful as well as problematic. Showing many things at once reflects the nature of lived experiences, which is impossible to communicate through textual narratives (Marion\& Crowder 2013). Marion and Crowder's (2013) point is that 'the meaning (italics in original) of an image [photograph] depends on the stimulus value it has for someone' (p.33). They mean that treating photographs as data leads us in extracting two perspectives 
of meaning; etic and emic. This argument corroborates with the notion of ethnicity which is self-conscious, self-aware and emanates from ongoing interaction with ethnic outgroups in a given sociopolitical context. Another way of facilitating an understanding of emic meaning a photograph embodies in qualitative research is through elicitations.

The way the social phenomena are interpreted by qualitative researchers produces controversy on the meaning of fact, truth and reality. Participatory and interactive nature of such research raises the question on universality of an interpretation but gets the researchers delve into the deeper understanding of the problem. Moreover, some qualitative researchers prefer to engage in developing general laws that govern our social life by entering into the people's stories. Photography and such other methods facilitate these researchers to establish connection with the events and subjects such as in grounded theory research.

\section{Photography in Grounded Theory Method}

Grounded theory method has not yet started to use significant amount of visual data such as still and motion pictures despite it has already occupied dominant space in recent qualitative research practices. To speak simply, grounded theory method is a reiterative process of generating theories from empirical data through research (Konecki, 2011). It is a reiterative process in a sense that a researcher in grounded theory method has to move to and fro frequently from analysis and data collection. Here, analysis and data collection become overlapping processes, not ordered stages.

GTM [grounded theory method] is very popular among qualitative researchers. It gives the possibility to create theoretical statements during empirical investigation. Researchers become more courageous in the formulation of generalizations based on qualitative data. It also provides tools for researchers to analyze qualitative data in a more rigorous way while giving them some freedom to decide the direction of analysis (Konecki 2011, p. 133). Everything that helps generate theory can acquire the status of data in GTM (Glaser, 2002). GTM researchers can rely on everything such as newspaper, interviews, books, internet, archival documents, 
paintings and photographs to generate categories and develop their properties (Konecki, 2011). Though not used sufficiently till now, photographs come to be the important data in GTM. The reiterative and subjective nature of GTM brings it closer to the notion of identity and turns to be an appropriate tool for research on the issues like ethnic identity construction on the one hand; and it rests on qualitative sources of data such as photographs on the other. Thus, simply, GTM, identity and photography constitute intertwining components of a qualitative research. To date serious debate has not been initiated on how the analysis of visual data can be integrated into grounded theory research. But few initial efforts have been made such as by Konecki.

Konecki has identifies five potential combinations in which visual data including photography can be brought together. The first is to analyze visual data as 'auxiliary materials'(emphasis in original) to generate theories from social processes (Konecki, 2011, p.137). While doing research on the issues such as ethnic identity, the least we can do is to use photographic analysis as a supplementary of textual analysis. Konecki (2011) believes that the other possible combination of visual data research and GT analysis is to use the "visual as the main source of empirical materials'(emphasis in original) (p.137). In this case, textual data come to be auxiliary part of visual data analysis and largely has been used to investigate interactions between humans and animals (Konecki, 2008a; Konecki, 2008b cited in Konecki, 2011). The third option is to use 'visual data alone' without any other supporting data such as ethnographic and interview. This is the most difficult and rarely practiced in GTM so far. The fourth is the use of "visual data either as an auxiliary or as the main source of, but data only in the analysis of visual dimension of actions and interactions'(Konecki, 2011, p. 137). The last possible combination is 'using visual data to track visual actions and interactions' (ibid), which is possible through photo albums, photo blogs or photo sharing in social sites in internet.

The above arguments on visual data and GTM can be replicated in our discussion on utility of photography in qualitative researches. For instance, photographic analysis of ethnic activities 
and presentation of ethnic self of the people through photographs can provide supplementary information to the textual analysis of identity formation. This does not mean that ethnic attire merely reflects the image of the ethnic self of the people but the central question is how ethnic people perceive photography at large and how they want to be exposed before others through photographs and images, or how they respond their imagery representation in larger social milieu. These questions again bring the notion of interpretation of photographs into centre of discussion. The point is that the photographer's and etic viewers' interpretations are not only the facts or realities, rather these facts or realities those are partial in themselves, come also from the interpretations of ethnic subjects. So, photographic study of ethnic identity construction should be able to extract the second layer of interpretation from the complex interplay of photographer's, viewers' and ethnic subjects' tripartite interpretations on ethnic identity, which is an outcome of constant interplay of these interpretations.

\section{Possibilities of Photographic Practice in South Asian Ethnicities}

Either photographs or other imagery representations; use of images in sociological research is the least discussed area in south Asia. Although photographic practice was introduced in south Asia by colonial administrators since its early years, rare cases of using photography as a primary method of research is found in the studies on south Asian ethnic diversities. The way the ethnicity and ethnic groups are presented in posters, media photos and such other imagery forms can be taken as one of the components of research on ethnicity. In post-colonial south Asia ethnic concerns have occupied ample space in the media and similar forms of social discourses. To a great extent, the media discourses through photographic representation have contributed in shaping particular identity of certain ethnic groups.

As early as in 1868 John Forbes Watson and John William Kaye came up with the first volume of a book entitled The People of India subsequently accompanied by other seven volumes until 1875 . These volumes contained 468 annotated photographs of various 
Indian castes and tribes. The first photograph in the first volume of this book is of Sonthal male (nowadays familiar as Santhal) and the chapter is dedicated to introduce Sonthals (Watson \& Kaye, 1868). The eight volumes of the book followed both textual and photographic representations provide socio-cultural and racial/ physiological accounts of Indian tribes.

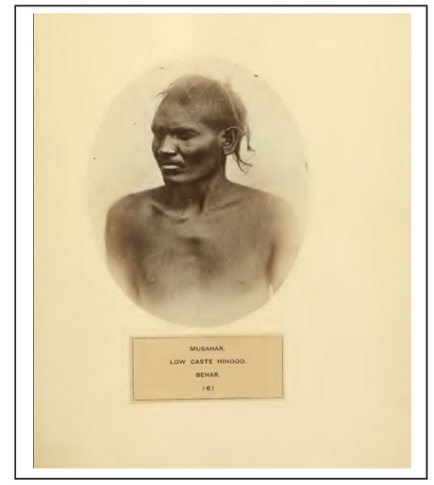

Musahar a low caste Hindu

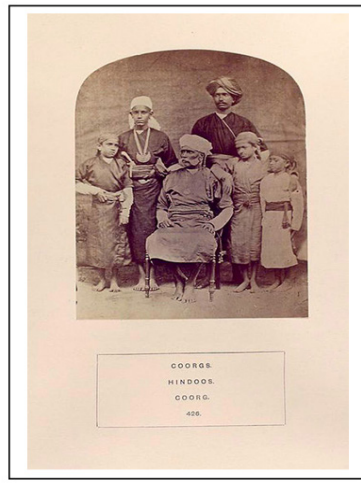

Members of the Coorg community

(Source: The people of India [Watson and Kaye, 1868-75 from www.wikkipedia.org])

The book is a classic instance of visual representation of various south Asian tribal identities through the western eyes. Since then sea change in the process of identity construction on ethnic ground has been observed. Tribal identity and ethnic identity cannot be synonymously understood, primarily since the labels 'Tribe' and 'Tribal' are western colonial denomination to the yet to be modernized groups.

Another classical work on Nepal by Fancis Hamilton (Buchanan) published in 1819 An Account of the Kingdom of Nepal has included few engravings of few places of Nepal. These engravings provide vivid images of early Nepal no less than by textual interpretations of those places and objects (see Hamilton, 1819).Pictorial presentation of the facts had already been taken into consideration largely by western ethnographers, travelers and colonial administrators.

For the first time, photography in Nepal was introduced by a British photographer named Clarence Comyn Taylor in 1863 when he had been requested to take photos of various hill tribes by British Administrators from Calcutta through George Ramsay, the British 
Resident in Nepal. These twenty photographs by Taylor can be found in the second volume of The People of India (photograph no. 58 to 77) along with short descriptions (Onta, 1998). Early photographers in Nepal largely found engaged with either family photographs or travel and trekking photographs. It was substantially limited within the Rana rulers and aristocrats of Kathmandu and rarely accessible to the commoners. Despite for few westerners, photography did not become a means of capturing the ethnic diversities among Nepalese photographers. Ethnographic photography in Nepal during later half of nineteenth century and first half of the twentieth century could not be the major part of photographic consumption (Onta, 1998). But in latter decades, one has ample opportunities of studying 'how photography has been implicated in the politics of nationalism and ethnicity as they have been played out in the public media' especially after 1990 era (Onta, 1998, p. 209).

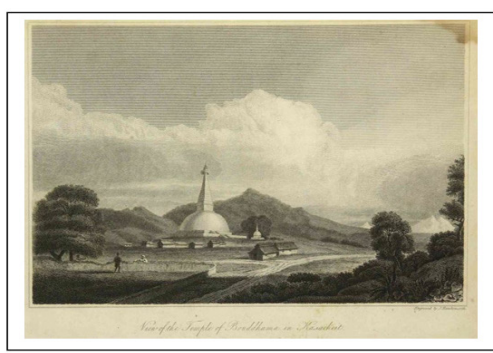

Temple of Bouddhama in Kasacheit [sic]

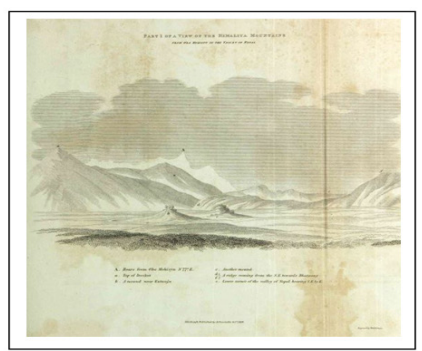

View of the Himaliva [sic] Mountains

At least two things have to be noted here. First, these early works were primarily travel descriptions, but not outcomes of sociological and anthropological researches except few ethnographic works. Second, the images in these types of works were largely supplementary to the textual description of travel accounts and purely representation of western values. Since the discovery of camera and photography in 1840s western ethnographers, travelers and administrators who were interested on south Asian society and culture considerably used pictures and images in their scholarly works. The above works are two instances only. There are other several works on south Asian communities done in the similar scale and forms, which largely have used photographs and images. 
These instances of early works, at least, suggest the possibilities of photographic study to understand the construction of selfhood among south Asian ethnic groups who have made the identity formation an inalienable part of their socio-cultural and political life in latter decades. But, the lack of comprehensive sociological works of such types in these decades makes the possibilities more challenging. Since the notions of ethnicity and ethnic identity are the products of modern nation building process, it is hard to seek connection between ethnic identity formation and early sociological and anthropological works. But now a days, reality has been upside down. The debate on nation-state, nation building and ethnic nationalism are the key concerns of south Asian social and political life. Ethnic politics among different cultural groups is unavoidable fact in South Asia. As a result, ethnic exposure in different forms such as dress, dance, art, rituals, language and political representation has great extent reshaped the social interaction. Representation of these things in photography considerably provides a synopsis of how people's identities are disseminated not only outwardly but how emotions are also embedded there.

For a sociologist photographs below are not only photos of two different ethnic groups in their own traditional attire. Such photographs of ethnic people tell more than simply outward images but also are enriched with several cultural, religious and emotional elements. They are embodied with rich meanings. A researcher can widen the scope of his/her understanding of an ethnic identity by looking at the pictures of an ethnic group. For instance, by studying these two images, we can make that how materialism, art, rituals, emotions and collective awareness are expressed through ethnic identity.

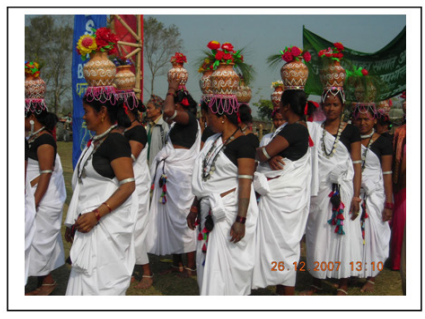

Tharu women of Nepal

Source: www.ourtourismnepal.blogspot.in ${ }^{2}$

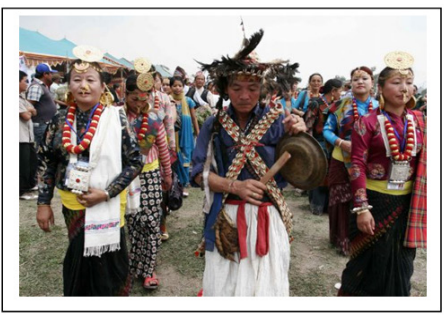

Limbus of eastern Nepal in a cultural dance Source: www.english.sina.com ${ }^{3}$ 
South Asia contains intricate network of various socio-cultural and ethnic identities. The complexity has extended from everyday lives of the local population to macro socio-political structures even crossing national boundaries (Hilali, 2005). For a social researcher interested in south Asian ethnicities, this diversity and complexity become rich source of data as well as opportunity of identifying models for addressing ethnicity based social problems. In most of the south Asian nations, ethnic nationalism has become a powerful political and social force, which not only has shaped inter-state relations but has also proliferated 'a movement of collective protest and self assertion against the existing distribution of power within and between states' (Hilali 2005, p. 55). Ethnic groups, for Barthes (1969) culture bearing units, are no more the same in south Asian context, but equally are key actors in larger political setting.

The region has already faced several cases of ethnic conflicts rooted in the idea of ethnic identity during the last sixty years and is one of the major challenges of the countries even today (Baqai, 2004: Hilali, 2005). This polarization has weakened the capacity of collective action, provoked inter-group antagonism and undermined the social harmony and solidarity. Furthermore, this identity debate has produced ample opportunities and challenges to the sociologists. Few of them have already worked on the issues to some extent and few others are still engaging. Though these researchers largely relied on textual interpretation of ongoing ethnic discourse in south Asia, they have not totally underscored the importance of photographic researches on identity movement.

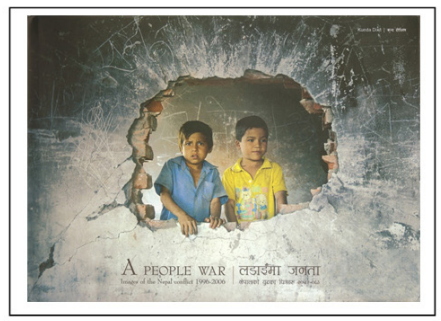

Cover page of 'A People War'

Image: www. books.scoop.co.nz

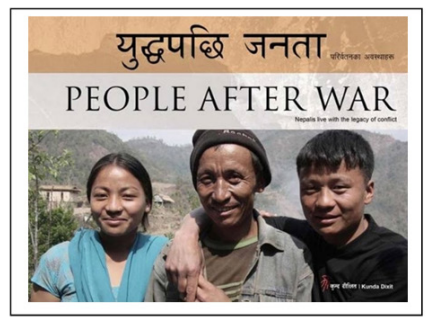

Cover page of 'People After War'

Image: www.therightsexposureproject.files.wordpress.com ${ }^{5}$

One of the imminent journalists of Nepal, Kunda Dixit published a pictorial book entitled 'a people war' in 2006 containing images of 
Nepal's civil conflict 1996-2006 taken by different photographers and journalists. Subsequently he published other two similar volumes entitled 'Never Again' and 'People after War'. Though the focus of these photographs is on Maoist war and its aftermath in Nepal, the close observation of these pictures gives a comprehensive glimpse of ethnic discourse experienced in Nepal. These few instances are no more than an effort of instigating discussion on the potentialities of photographic research is south Asian context where such practice is still in question.

Sociological researches in south Asia up to this point is far behind in producing research works and materials on photography and ethnicity despite the fact that plentiful opportunities of doing such researches. Nevertheless, various disciplines have been increasingly making use of the photographs on a par with increasing access to the modern technologies, which could project the possibilities of photographic practice on ethnic issues. Ethnic diversity of south Asia is not constricted only in establishing cultural distinctness of a group; it has moved beyond this and become ethno-political movement as well. As a result, ethnic narratives have gaining political recognition on the one hand and have also occupied a central space in the larger south Asian socio-political discourse; either they be Sinhalese-Tamil contention in Sri Lanka, casteethnicity debate in Nepal, Lhotshampa-Ngalops relation in Bhutan, Chakma minorities in Bangladesh, ethnic minorities in north-east India and Hindu minorities in Pakistan. In exploring the people's narrative in such ethnically complex circumstances, a researcher requires strict qualitative and participatory tools of research such as RRA, PRA, interviews, photo elicitation in which photography complements these needs by facilitating rapport and generating emotionally shaped nexus with the ethnic communities under study.

\section{Concluding Remarks}

There is no reason to avoid the use of visual aids in sociological studies since they have already entered into the discipline long before. Rather, one should note that sociology and photography, both, engage with social life of the human beings and make their best efforts to bring the intricacies into the fore. Because of the rapid 
development of science and technology the use of camera has been easily accessible to the larger sections of the population. This has not only made photography a part of everyday life but also opened up the huge possibilities of understanding of social life closely and minutely. As a result, nowadays, social sciences such as sociology, anthropology, media studies, and political science have been using large amount of photographs in their researches and publications.

The very nature of sociology, as a science of social interaction and relationships, gets it linked with people's everyday experiences shaped by the social circumstances. Qualitative sociologists aim to extract the layers of meanings from these experiences with the help of different tools and techniques. They need such tools which could narrate people's stories and help them delve into the deeper understanding of social phenomena. Photography could be one of those tools since it is such an entity that is always embedded with rich meanings. The time, context and narrative feature of photography make it rich. That is why the legitimacy of visual sociology and visual anthropology has already been accepted in the larger scope of sociology and anthropology.

Photographs not only capture the physical appearances, scenes and movements but also capture the emotions, feelings and experiences reflected in gestures and expressions, and help us relate these things. Photography, thus, can capture the everyday life experiences of people who are always engaged with various identities. The ethnic identity which is largely culturally rooted and political shaped in nowadays plays an important role in shaping people's experiences. Societies such as south Asia enriched with cultural and ethnic diversities on the one hand and suffered from ethnic contention and identity struggle on the other could provide sociologists a best platform to study ethnic groups by bringing them inside the frame of camera.

\section{Notes:}

${ }^{1}$ For further detail on IVSA, please check: http://visualsociology.org/about.html (accessed on 13 February 2014).

${ }^{2}$ For access: http://ourtourismnepal.blogspot.in/2010/04/description-of-tharus-innepal.html (accessed on 10 Feb 2014) 
${ }^{3}$ For access: http://english.sina.com/life/p/2010/0417/314762.html (accessed on 10 Feb 2014)

${ }^{4}$ Check also: http://books.scoop.co.nz/wp-content/uploads/2010/02/People-warpc.jpg (accessed on 10 Feb 2014)

${ }^{5}$ Check also: http://therightsexposureproject.files.wordpress.com/2009/11/peopleafter-war.jpg (accessed on 10 Feb 2014)

${ }^{6}$ For detail see:

http://www.apeoplewar.com.np/ (accessed on 10 February 2014)

http://www.nepa-laya.com/pub_detai_awar.html (accessed on 10 February 2014)

\section{References}

Baqai, H. (2004). Role of Ethnicity in the Conflict Spectrum of South Asia. Pakistan Horizon, 57(4), 57-68.

Barth, F. (1969). Ethnic groups and boundaries: The social organization of culture difference. London: Allen \& Unwin.

Barthes, R. (1984). Camera Lucida: Reflections on Photography, Becker, H. S. (1974). Photography and Sociology. Studies in the Anthropology of Visual Communication, 1, 3-26. Retrieved 01 23, 2014, from http://lucy.ukc.ac.uk/ becker.html\#2

Campbell, D. (2010). Photography and narrative: What is involved in telling a story? Retrieved 01 27, 2014, from david-campbell.org: http://www.david-campbell. org/2010/11/18/photography-and-narrative/

Campion, B. (2007). Photography as a method of Visual Sociology: An investigation of the potential of still photography as a method of visual sociology. An unpublished paper submitted for Master of Fine Art to The University of New South Wales, Australia.

Collier, J., \& Collier, M. (1986). Visual Anthropology: Photography as a Research Method. Albuquerque: University of New Mexico Press.

English, F. W. (1988). The Utility of the Camera in Qualitative Inquiry. Educational Researcher, 17(4), 8-15.

Glaser, B. G. (2002). Constructivist grounded theory? Forum: Qualitative social research. Retrieved 2 4, 2014, from http://www.qualitative-research.net/index. 
$\mathrm{php} / \mathrm{fqs} /$ article/view/825

Hamilton, F. (1819). An account of the Kingdom of Nepal and of the territories annexed to this dominion by the house of Gorkha. Edinburgh.

Hilali, A. Z. (2005). Political and Ethnic Waves in South Asia.

Pakistan Horizon, 58(3), 55-75.

Kinsman, P. (1995). Landscape, Race and National Identity: The

Photography of Ingrid Pollard. Area, 27(4), 300310.

Konecki, K. T. (2011). Visual Grounded Theory: A Methodological

Outline and Examples from Empirical Work. Reviza Sociologiju, 41(2), 131-160.

Marion, J. S., \& Crowder, J. W. (2013). Visual research: A concise introduction to thinking visually. London:

Bloomsbury Academic.

Murray, J. K. (1995). Buddhism and Early Narrative Illustration in China. Archives of Asian Art, 48, 17-31.

Pimenta, S., \& Pooviah, R. (2010). On defining visual narratives. design thoughts, 25-46. Retrieved 01 28, 2014, from http://www.idc.iitb.ac.in/resources/designthoughts.html

Pinney, C. (2011). Photography and Anthropology. New Delhi: Oxford University Press.

Schulze, S. (2007). The usefulness of reflexive photography for qualitative research: a case study in higher education. South African Journal of Higher Education, 21(5), 536-553.

Schwartz, D. (1989). Visual ethnography: Using photography in qualitative research. Qualitative Sociology, 12(2), 119-154.

Searle, J. R. (1995). The social construction of reality. London: Penguin Books.

Watson, J. F., \& Kaye, J. W. (1808). The people of India, Vol 1-8. Waterloo: W. H. Allen and Co.

Wolbert, B. (2000). The Anthropologist as photographer: The visual construction of ethnographic authority. Visual Anthropology, 13, 321-343. 